\title{
E-commerce for Developing Countries: Expectations and Reality
}

\section{John Humphrey, ${ }^{*}$ Robin Mansell, Daniel Paré and Hubert Schmitz}

\section{Introduction}

Business-to-business (B2B) e-commerce has been heralded as a radical change in the way that firms trade with one another. In the late 1990s, B2B e-commerce applications were being promoted as tools that would facilitate the access of producer firms in developing countries to global markets. This vision of $\mathrm{B} 2 \mathrm{~B}$ e-commerce was driven by the idea that the internet provides an opportunity for firms to trade directly with each other, buying and selling products online, bypassing intermediaries, and gaining much easier access to global markets. The internet would enable firms in developing countries, including small and medium-sized enterprises (SMEs), to find new customers quickly and cheaply: 'the next vendor is only a mouse-click away' (UNCTAD 2000: 18).

These expectations were not based on hard evidence of B2B e-commerce use in either developed or developing countries. An analysis of B2B e-commerce in practice, based on a study of internet-based "e-marketplaces" and the use of the internet for business purposes by garments and horticultural firms in three developing countries Bangladesh, Kenya and South Africa - leads to a very different conclusion.

Expectations prevalent in e-commerce-related business and in development agencies during and even after the dot.com boom have been open to question. There is little evidence that firms are using the internet to find new customers and suppliers, or to buy and sell goods through e-marketplaces. Nevertheless, the internet is becoming an important business tool. It is becoming an important means of managing and coordinating business between firms with established business relationships. It is the existing customer who is a "mouse-click away".

This use of the internet is not the result of business technophobia or the inadequacies of the supporting business environment for B2B e-commerce. The pattern of business use of internetbased applications is created by the communications advantages of the internet and its enormous disadvantages in creating trust between firms. E-marketplaces have not been able to develop trust mechanisms, and the costs of transacting business online remain very high.

\section{Expectations for B2B e-commerce}

At the end of the 1990s, many analysts and policy makers believed that B2B e-commerce would lead to a radical change in the way that enterprises trade with one another. E-competitiveness would become essential for access to global markets. As UNCTAD put it, 'enterprises in developing countries that are or plan to be involved in international trade need to start incorporating information and communication technology (ICT) and the internet into their business models in order to stay competitive' (2001: 18).

Use of the internet was expected to reduce the effect of geographical distance, providing better information on final markets and lowering the costs of registering a presence in global markets. This was expected to lead to substantial benefits in the form of improved access to international markets and strengthened competitiveness. The ability of internet-based B2B e-commerce systems to facilitate business linkages across the world seemed to open up new possibilities even for small and isolated rural enterprises and communities.

The way B2B e-commerce was expected to operate can be summarised in four propositions, taken from the policy literature of development agencies, but reflecting broader business and government views about the potential for e-commerce: 
1. E-commerce works through many-to-many e-marketplaces. B2B e-commerce marketplaces are online spaces where many buyers and sellers can come together in one trading community and obtain sufficient information to make decisions about whether to buy or sell. Manyto-many e-marketplaces would become the dominant component of e-commerce activity:

E-markets involve a large number of buyers and sellers that engage in many-to-many transactions and relationships. They create a trading community in which buyers' orders are matched with sellers' offers and the trading partners benefit from other forms of collaboration. (UNCTAD 2001: 65)

2. E-marketplaces and business service providers would provide the information and services needed by buyers and sellers so that they can decide to carry out a transaction online and then make arrangements for payment and delivery.

3. B2B e-commerce offers two important advantages for developing country firms. First, e-commerce-related transaction costs are less sensitive to distance than traditional marketing channels, so access to global markets is made easier. Second, by simplifying and making market channels more efficient, B2B e-commerce should enable developing country firms to retain a larger share of the final consumer price of products. The process is not necessarily one of disintermediation, but rather one of more efficient, internet-based intermediation:

Traditional marketing and export channels [for primary products] tend to be inefficient and dominated by multiple intermediaries ... Developing countries, using existing local commodity exchanges and commodity export associations as a foundation, can use B2B online trading as a means of transforming existing commodity marketing systems to great advantage. (UNCTAD 2001: XXII)

4. B2B e-commerce particularly helps smaller firms to enter global markets. Reductions in the costs of accessing global markets are particularly important for SMEs:

E-trade opens new commercial opportunities to the export-oriented enterprise. In particular, it empowers the small and medium-sized enterprise (SME), allowing it to participate in international markets where previously market entry and promotion costs were prohibitive. It enables the firm to source production inputs more expeditiously, to streamline (i.e. eliminate intermediaries) its own supply- and export-distribution chains and to reduce business transaction costs. (International Trade Centre 2000: 8)

This view of how B2B e-commerce works has analogies to business-to-consumer e-commerce sites such as Amazon. Working online, it is possible to make decisions that result in products being purchased and delivery and payment being executed. B2B e-marketplaces such as efoodmanager.com or rooster.com were promoted as having the same potential during the dot.com boom.

Such a perspective on the developmental potential of B2B e-commerce has direct and significant policy implications for developing country governments. E-commerce is seen as essential for maintaining and increasing access to global markets, and it has particular benefits for SMEs. Governments have particular responsibility for two aspects of the environment needed for effective online trading. First, some B2B e-commerce transactions are complex and information-intensive, requiring a quantum leap in telecommunications capabilities. Governments should ensure that telecommunications capabilities are sufficiently developed to provide low-cost network access. This could best be achieved through competition, market liberalisation and reducing tariffs on ICT hardware and software. Second, online trading has to be supported by a legal system that recognises and enforces the validity of online contracts through such mechanisms as digital signatures, secure settlement procedures, anti-fraud measures and mechanisms for redress. Developing country governments should invest resources in developing and promoting these capabilities. Otherwise, firms might find themselves at a disadvantage and be marginalised from the internet boom.

\section{Investigating the reality of e-commerce}

The high levels of optimism about the potential benefits of B2B e-commerce were not accompanied by any substantial evidence on whether and how firms were using it. The evidence base for optimism about e-commerce development appears to have been based upon anecdotes about the development of particular B2B e-marketplaces, a small number 
of projections of likely e-commerce growth that appear repeatedly in policy documents ${ }^{1}$ and the use of internet infrastructure indicators, such as the spread of telecommunications services and internet hosts, as proxies for real business transactions.

The real extent of the use of $\mathrm{B} 2 \mathrm{~B}$ e-commerce by firms in developing countries using the internet for business transactions has been largely undocumented. The research findings reported here take a step towards remedying this deficiency by examining two aspects of B2B e-commerce.

\subsection{E-marketplaces and their attributes}

If businesses were to use e-marketplaces to buy and sell products online, what types of services would they require? A firm thinking about using the marketplace might well look for the following:

- a means of making payments for goods and services

- for the buyer, some means of verifying information provided about products being offered for sale

- for the seller, some means of ensuring that payment will be made

- some assurances about the bona fides of firms offering to do business

- some system for redress if disputes arise

- some support for arranging the physical transfer of products from seller to buyer.

A survey of 184 e-marketplaces dealing in apparel and horticultural products was carried out in 2001. Their transaction structures and the services that they offered were examined. In addition, key informants involved in B2B e-marketplaces in Europe were interviewed.

\subsection{Use of the internet by developing country firms}

The second component of the research involved interviewing senior managers and owners of apparel and horticultural enterprises in developing countries about their use of the internet for business. These interviews focused on business activity, use of email and websites, experiences with buying and selling products using the internet and motivations for using or not using the internet in their businesses. Garments and horticulture were chosen for the study because of their importance for developing country exports. It could be argued that both sectors tend to produce differentiated products that are hard to trade online because of their lack of standardisation. This might imply that e-commerce opportunities will emerge in other sectors. However, analysis of online trading sites in Europe and North America provides little support for the view that standardised products are easily tradeable online. Many open marketplaces have collapsed, and even for standardised products, issues such as quality, delivery and response times remain important. ${ }^{2}$ It would be wrong to believe that there is extensive potential for open, B2B e-marketplaces trading in standardised products that a study of garments and horticulture would fail to capture.

\section{E-marketplaces and their attributes}

The first and most important conclusion from the study of e-marketplaces is that the vast majority do not support online trading. They are informationoriented rather than transaction-oriented. Just over three-quarters (77 per cent of the 184 e-marketplaces) could be classified as "dating agencies". These allow "introductions" to be made between firms, but once brought together, it is up to the firms themselves to develop a relationship resulting in the transaction. These "dating agencies" were of three main types: ${ }^{3}$

1. Trade leads/classifieds. Buyers and/or sellers post messages to an online forum or to individual members indicating a desire to buy or sell items.

2. Direct buyer and seller links. These provide a means for sellers to post direct links from an "e-marketplace" to their own company websites. Potential buyers can follow these links to the vendor's website.

3. Requests for quotes. This consists of a seller or buyer posting a message to a forum within an online environment or to individual members, indicating a desire to buy or sell items.

These e-marketplaces enable firms to identify and contact potential trading partners, but this is only the start of the business process. The followup to an initial contact generally takes place through other channels such as email, a hyperlink, the telephone, fax, or the post. The e-marketplaces do not support online trading.

It follows from this that the marketplaces do not 
provide the broad range of services required to support online trading. The findings from the survey were clear in this respect:

- Some 80 per cent of the e-marketplaces surveyed left the responsibility for arranging payments to the trading parties. The site of one marketplace provider stated: '[Company A] is a neutral party in all transactions. [Company A] does not assume legal responsibility for items lost, damaged, not delivered, etc., nor does it assume responsibility for items not paid for. Contracts are between buyer and seller only'. This was a typical position and it is designed to prevent e-marketplace providers having legal responsibility for the behaviour of firms using the marketplace. Only 7 per cent of sites provided facilities for online payments.

- E-marketplaces were not in a position to screen participating firms. According to the Chairman of one leading global e-marketplace, registration had to be very simple and quick (a matter of just a few minutes at most), otherwise potential marketplace users would not persist in trying to register. The dominant tendency is for free or very low-cost access to e-marketplaces resulting in a very minimal level of services provided. Where, for example, credit rating information on participating firms was available (on 17 per cent of marketplaces), this generally took the form of a link to a third party or "strategic partner" that would provide information for an unspecified fee. Like other internet-based service providers, e-marketplaces have struggled to persuade users to pay for services. A user survey by ECeurope.com Limited (Electronic Commerce Europe $)^{4}$ found that only 27.6 per cent of users would even consider paying 'a small monthly subscription fee if companies viewing and responding to your offers to buy and sell were required to go through a qualification process'.

- For the same reasons, few sites offered any independent verification of product information provided by sellers. In 2000 , some firms were offering to provide such services. The Swiss standards and certification company, SGS, developed a set of services for online trading, involving certification of firms to quality, environmental and labour standards, and was also prepared to offer services such as inspection of particular factories and procurement of product samples. ${ }^{5}$ However, the take-up of the services for online trading appears to have been extremely limited.

Genuine online trading through e-marketplaces where purchases can be made with the click of a mouse do exist. The Teleflower Auction (TFA) in Amstelveen and the online auction system for trading fish created by Pan-European Fish Auctions (pefa.com) are two examples. However, the closer one gets to purchasing with a click of a mouse, the more complex the supporting infrastructure must be. On the one hand, buyers have to be registered and have payment guarantees in place. On the other hand, sellers and their products have to be carefully vetted and assessed. In the case of the Amsterdam flower auction, for example:

One of the main propositions of the TFA was that the quality of the flowers determines the buyers' trust in the TFA concept. TFA's motto is 'Buyers have to trust the quality blindfold' because buyers cannot physically see the product anymore. Still, buyers who are nearby TFA can inspect the imported flowers; 30 per cent of the buyers do so regularly. Reliable product information and stable quality control are essential. Quality control is done by TFA's quality inspectors at the grower's place at the distribution point in Nairobi (Africa), and at TFA in Amstelveen. (van Heek and Ribbers 2000: 361)

The intermediary, far from disappearing, plays a pivotal role by organising the value chain and providing quality control in both Nairobi and Amstelveen. The buyers, too, are mainly located within a few kilometres of the auction house and are able to pick up the flowers that they purchase. In the case of pefa.com, the critical role of quality control is performed by the auction houses at the fishing ports, who verify the species, quantity and quality of each lot to be auctioned, while pefa itself provide guarantees of payment to suppliers. Buyers and sellers may not know each other, but both are known to the intermediaries and access to these e-marketplaces becomes more and more restricted as online functionality increases.

The key point here is not that the marketplaces found in the survey do not correspond to the expectation of many-to-many, transaction-oriented 
e-marketplaces outlined earlier. The critical point is whether this non-correspondence has implications for the overall growth of B2B e-commerce, the types of firms that are able to take advantage of it, the extent to which the potential benefits for developing country firms still apply, and the policy implications of the dominance of information-oriented e-marketplaces.

The first critical implication concerns the potential reduction in transaction costs supposedly offered by online trading. The "dating agency" model does not reduce these costs to anything like the expected extent. In fact, once a contact has been made, the offline costs are very similar to any business generated through a trade directory or a direct inquiry.

The case of one of the few firms in the survey that was generating a significant share of its overall business using postings on information-oriented e-marketplaces illustrates the problem. This Nairobibased firm was a trader in fruit and vegetables. Its turnover was very small (less than $£ 20,000$ per annum), but it was generating one-third of its business through a variety of e-marketplaces. The owner of the business described how he deals with email inquiries generated by his marketplace postings:

- Discard any inquiry from a firm with a hotmail or Yahoo email address.

- Check to see if the company making the inquiry has a website and consult web-based Yellow Pages business directories.

- Consider the product requested. It is better to deal with more robust products (for example, fruit rather than vegetables such as green beans which last days rather than weeks), as the logistical requirements are simpler.

- Check the quantities, decide on sea or air transport and then contact a local shipping agent to find out about freight rates, timing, etc.

- Check on the internet to see who the competitors are in the market being supplied and in particular, to see when there are supply gaps in the market.

- Follow up the inquiry with a quote based on the cost of local sourcing, packaging, freight costs and the exporter's mark-up. Contact with the customer is predominantly by email.

- Deal directly with the customer on the case-bycase basis. The customer might require a physical sample to be sent or a particular type of packaging to be used.
- Arrange payment. After some unfortunate experiences of non-payment both with e-marketplaces and traditional customers, the exporter was demanding a 50 per cent downpayment and the remainder on proof of shipment.

Moving from inquiry to completed transaction involved some email and internet use, but in many respects the process was similar to dealing with a traditional inquiry and involved considerable effort. This is not an instance of immediate and low-cost access to global markets.

Not surprisingly, this firm was a specialist trader, with the contacts needed for arranging transport, payment, etc. This is the second implication of information-oriented e-marketplaces. Their use requires specialist skills and, as a result, many of the users are traders rather than producers. The survey of users conducted by ECeurope.com Limited (Electronic Commerce Europe), ${ }^{6}$ found that more than half of its registered users classified themselves as trading houses, importers, exporters agents or distributors.

This means that developing country producers are not likely to bypass intermediaries when using information-oriented e-marketplaces. These intermediaries have complementary capabilities needed to make dating agencies work, including information about payment and logistics, trade regulations, etc. At most, producers from developing and transition economies might be able to gain easier access to a wider range of intermediaries, thus achieving the goal of widening access to global markets.

\section{Use of the internet by developing country firms}

A total of 74 exporting firms in developing countries were interviewed about the use of the internet for business. The first three conclusions of the survey were:

- A surprisingly large minority of the firms interviewed had registered with at least one of the marketplaces. Almost one-quarter of firms (17 cases, 23 per cent), had registered with a marketplace.

- Of the 17 firms registering, seven had succeeded in making at least one sale.

- The smaller firms in the sample were much more likely to have registered with an e-marketplace than the larger ones. Nearly 40 per cent of the 
smaller firms had registered, but only 10 per cent of the larger firms. However, firm size did not play a role in whether those who registered were able to complete a sale.

In addition to registration with e-marketplaces, some firms also scanned marketplaces looking for buyers and sellers or developed their own websites. This provides clear evidence that firms were prepared to experiment with internet business opportunities. Nevertheless, the clear result of the survey is that for almost all the companies concerned, buying and selling products using the internet to find customers or suppliers was either not part of their business strategy or involved occasional and small transactions that were not central to the overall business.

There are two reasons for this. First, the internet did not provide an efficient means of doing business with new buyers or suppliers because of the problems highlighted in the previous section. The transaction costs involved in arranging small transactions were very high - precisely the opposite of what was expected from B2B e-commerce. Second, suppliers and buyers had developed systems of working together that were quite the opposite of what was promised by B2B e-commerce. Business was based on transfers of complex, hard-to-codify information and relationships built up over time. Even for standard inputs, using e-marketplaces represented a big risk. The point is summarised succinctly by Tregurtha and Vink (2002):

The principal reason the other growers gave as to why they had never used the internet to sell any of their products internationally relates to the fact that the existing horticulture marketing chain is fairly entrenched as a business model and that no incentive to re-engineer the chain currently exist.

Similarly, Moodley et al. note that the requirements of export customers in the USA and EU involved supplier screening, exchange of detailed product specifications, etc. These could not be managed through e-marketplaces:

The EU and US buyers require prospective suppliers to undergo an exacting certification process, provide detailed production specifications, demand detailed quality control (QC) to ensure that the supplier conforms to the technical expectations and quality requirements of the buyer, exacting laboratory tests, and frequent updates on the product's progress (covering pre-production procedures, coordination of input deliveries, production schedules, methods and timing of garment deliveries, etc.). (Moodley et al. 2003: 28)

In spite of this, the internet did appear to be transforming business operations in two important ways. First, the use of email for maintaining contact with suppliers and customers was extremely widespread. Just over 80 per cent of firms said that they used the internet always or frequently for placing or accepting orders. Rather than finding new customers and suppliers through the internet, firms were using email to change the way they were working with their existing customers and suppliers. One clear reason for this was cost. Using local internet service providers was much cheaper than international telephone or fax calls. As important, email and email attachments offered completely new opportunities for transferring information. One large Kenyan exporter sent spreadsheets with planting schedules, output projections and information about how containers were being packed for overnight airfreight to its UK importer on a daily basis. Similarly, three South African horticultural producers mentioned the use of digital images sent by email as a way of indicating quality problems and increasing trust along the value chain (Tregurtha and Vink 2002: 15). According to one UK horticultural importer, it seems likely that web-based systems would be put in place to provide exporters with information about schedules, quality, etc.

Coordination between buyers and suppliers was also seen in the domestic part of the South African garments industry. According to Moodley et al. (2003: 26-27), stock control and replenishment orders were already being handled through electronic data interchange (EDI) with large retailers, and there were some signs of these closed, proprietary systems migrating to the internet. Once again, however, these systems do not generate new orders for suppliers. They handle relations with existing customers.

The second major development in business use of the internet, found just for a few firms but clearly evidenced by other sources, is the use of private, exclusive e-marketplaces by global buyers to distribute business among suppliers. Respondents 
from two South African garment firms had used the internet to link into the e-procurement systems of large retailers in the United States in order to bid for contracts. One had participated in a private internet-based "auction" organised by a large discount retailer in the USA, and the other firm had participated in a closed, forward auction through another US retailer's website.

Similarly, one Bangladesh firm had been invited to participate in a closed web-based bidding process by an international buyer that had invited a limited number of firms to participate in a bidding process. A second firm in Bangladesh had participated in a similar closed bidding process established by one of its French buyers. After having received product samples from the supplier, the French company invited the supplier to participate in its online auction. The auction was hosted by a local buying agent based in Dhaka, and all the local bidders had to be physically present at the local buying agent's offices at an appointed time to submit their tenders electronically. This firm had also been informed by Wal-Mart, one of its major clients, that it would be introducing a similar online bidding procedure for its suppliers.

Clearly, the global buyers that required close interactions with their suppliers (see the quote from Moodley et al. above) were beginning to promote competition with their supplies through these auctions. The development of such online bidding raises the prospect of small suppliers competing against each other for the business of large, powerful global buyers with the capacity to source from multiple companies in countries. The owner of the second of the Bangladesh firms stated that such auctions had a tendency to push prices down to very low levels. This is one of the reasons why large suppliers in developed countries have been reluctant to participate in private, exclusive e-marketplaces. Developing country suppliers may not have the luxury of resisting this trend.

\section{Policy implications}

The first, clear policy implications of these findings is that open forms of $\mathrm{B} 2 \mathrm{~B}$ e-commerce are not going to provide low-cost access to global markets for developing country SMEs. The marketplaces surveyed do not solve the problem of the high transaction costs involved in finding and doing business with overseas customers. Similarly, to the extent that the most rapid growth in B2B e-commerce is likely to be closed marketplaces, access to these marketplaces is based upon prequalification and the ability to meet the exacting requirements of global buyers. With or without the internet, these buyers increasingly look to large firms in developing countries. ${ }^{8}$

The findings also have clear implications for government priorities with regard to provision of internet access. First, the use of the internet for email, closed auctions and access to informationoriented e-marketplaces does not require high bandwidth for communication. Rather than develop infrastructure systems suitable for informationintensive communications, emphasis should be placed upon reliable, internet access available at low prices. Reliability is particularly important for firms that use the internet for day-to-day coordination or time-constrained transactions. ${ }^{9}$

Second, given the almost complete absence of online buying and selling, the investment of scarce resources in the development of a legal and regulatory framework for online payments and contracts would seem to be a misallocation of resources. It misunderstands the way businesses are likely to use the internet. The same applies for investments in a trust infrastructure.

Nevertheless, the internet is becoming important for business. Resources should be devoted to awareness, training and capacity building. Access to email, and probably in the future internet-based information systems, will become increasingly important for businesses. The availability of people able to develop and operate the systems will become essential for businesses.

The way B2B e-commerce has developed in the sectors and countries studied is the result of the way business relationships are managed. It is not the result of either a lack of a legal and technical infrastructure for e-commerce or the resistance of most business people to new technology. There is not a large potential demand for open forms of online buying and selling. The prospects for open, transaction-oriented e-marketplaces have been undermined by their failure to correspond to the way that most firms do business with other firms. Arm's length market transactions do occur in global markets, but only when the problem of trust is resolved.

Who is the partner and can promises about products and payment be kept? E-marketplaces have not solved these problems in a cost-effective 
manner. As important, a lot of transactions require much more complex transfers of information about product design, process, company capabilities, compliance with safety, labour and environmental standards, etc. This is why the larger horticultural producers in the survey ruled out either buying or selling products through

\section{Notes}

* This article is based on The Reality of E-commerce with Developing Countries, by John Humphrey, Robin Mansell, Daniel Paré and Hubert Schmitz (see Humphrey et al. 2003). The research for the report was financed by the UK Department for International Development (DFID). DFID supports policies, programmes and projects to promote international development and provided funds for this study as part of that objective, but the views and opinions expressed are those of the authors alone.

1. Companies such as eMarketer, Forrester Research, ActivMedia and IDC frequently projected growth rates of B2B e-commerce of 100 per cent per annum and these projections were repeatedly cited in policy documents.

2. See for example, Christiaanse and Markus (2003) and Desruelle et al. (2001).

3. These issues are discussed in more detail in Paré (2003).

4. The survey was sent to 2,000 registered users from whom 254 responses were received. The results of this survey are Copyright 2001 ECeurope.com Limited (Electronic Commerce Europe). All Rights Reserved. The authors thank ECeurope.com Limited and its Chairman, Jonathan Cutting, for permission to cite this material.

\section{References}

Christiaanse, E. and Markus, M., 2003, 'Participation in collaboration electronic marketplaces', paper presented at Annual Hawaiian International Conference on Systems Sciences, Los Alamitos, Hawaii, IEEE Computer Society Press, Vol IV

Desruelle, P., Verhoest, P., Ducatel, K., Burgelman, J-C., Bogdanowicz, M. and Punie, Y., 2001, 'Techno-economic impact of e-commerce: future development of value chains', Report on a Workshop Held at the Institute for Prospective Technological Studies EUR 20123 EN, Seville: European Commission Joint Research Centre (DG JRC)

Dolan, C. and Humphrey, J., 2000, 'Governance and trade in fresh vegetables: the impact of UK supermarkets on the African horticulture industry', Journal of Development Studies, Vol 37 No 2: 147-176 e-marketplaces. These did not provide the transactional environment they needed. Unless policies for promoting B2B e-commerce are tuned into the realities of "commerce" rather than hype of "e", they will continue to provide expensive solutions to the wrong problems.

5. This programme was presented by Gérald Houet-Dutruge of SGS at a conference on E-commerce for Agribusiness held in London in June 2000. For more details see the SGS on SITE (Safe internet Trade Environment) website www.sgs.com/SGSGroup.nsf/pages/ServicesOnline.html

6. See note 4 for details of this survey.

7. Although the respondents informally referred to these procurement systems as "auctions", they were not involved in competitive bidding. They provided a means for existing suppliers to submit tenders for production runs. The suppliers did not have access to any information about the prices that their competitors were quoting to the buyer. Once the tenders were evaluated by the buyer, the successful supplier was notified, usually via email and fax.

8. See, for example, the analysis of the impact of UK supermarket buying practices on the structure of horticultural export industry in Kenya analysed by Dolan and Humphrey (2000).

9. An attempt by one of these survey firms to participate in a closed auction in Dhaka was frustrated by a power cut at the time when the bid was to be placed.

Humphrey, J., Mansell, R., Paré, D. and Schmitz, H., 2003, The Reality of E-commerce with Developing Countries, London: Media Studies, LSE, www.gapresearch.org/production/ecommerce.html (accessed May 2003)

International Trade Centre, 2000, Export Development in the Digital Economy, Geneva: International Trade Centre, www.intracen.org/ execforum/ef2000/publication2000.htm (accessed November 2002)

Moodley, S., Morris, M. and Velia, M., 2003, 'E-commerce for exporting garments from South Africa: "digital dividend" or leap of faith?', IDS Working Paper 182, Brighton: Institute of Development Studies

Paré, D., 2003, 'Does this site deliver? B2B e-commerce services for developing countries', The Information Society, Vol 19 No 2, www.gapresearch.org/ produ ction/ecommerce.html (accessed January 2002) 
Tregurtha, N. and Vink, N., 2002, B2B E-commerce and the South African Horticultural Export Industry: Current Status and Future Directions, www.gapresearch.org/production/ecommerce (accessed September 2003)

UNCTAD, 2001, E-commerce and Development Report, 2001, Geneva: UNCTAD, www.unctad.org/ ecommerce/docs/edr01_en.htm (accessed January 2002)

UNCTAD, 2000, Building Confidence: Electronic Commerce and Development, Geneva: UNCTAD, www.unctad.org/ecommerce/ecommerce_en/do cs_en.htm (accessed November 2001)

Van Heek, E. and Ribbers, P., 2000, 'Experience with Electronic Auctions in the Dutch Flower Industry' in C. Westland and T. Clark (eds), Global Electronic Commerce: Theory and Case Studies, Cambridge, MA: The MIT Press: 355-365 